This item was submitted to Loughborough's Research Repository by the author.

Items in Figshare are protected by copyright, with all rights reserved, unless otherwise indicated.

\title{
The impact of alternate weekly collections on waste arisings
}

\section{PLEASE CITE THE PUBLISHED VERSION}

https://doi.org/10.1016/j.scitotenv.2012.12.024

\section{PUBLISHER}

(c) Elsevier

\section{VERSION}

VoR (Version of Record)

\section{PUBLISHER STATEMENT}

This work is made available according to the conditions of the Creative Commons Attribution-NonCommercialNoDerivatives 4.0 International (CC BY-NC-ND 4.0) licence. Full details of this licence are available at: https://creativecommons.org/licenses/by-nc-nd/4.0/

\section{LICENCE}

CC BY-NC-ND 4.0

\section{REPOSITORY RECORD}

Williams, I.D., and Christine Cole. 2019. "The Impact of Alternate Weekly Collections on Waste Arisings". figshare. https://hdl.handle.net/2134/34887. 


\title{
The impact of alternate weekly collections on waste arisings
}

Science of the Total Environment 445-446 (2013) 29-40

http://dx.doi.org/10.1016/j.scitotenv.2012.12.024

\section{AUTHORS}

I.D. Williams, I.D. a*, Cole, C. b

a Waste Management Research Group, Faculty of Engineering and the Environment, Lanchester Building, University of Southampton, University Rd, Highfield, SOUTHAMPTON,

Hampshire, SO17 1BJ, UK

b Centre for Innovative and Collaborative Construction Engineering, School of Civil and Building Engineering, Loughborough University, Epinal Way, Loughborough, LE11 3TU, UK

* Corresponding author. Tel.: +44 2380 598755; fax: +442380678606.

E-mail address: idw@soton.ac.uk (I.D. Williams).

\section{H I G H L I G H T}

Impact of introducing alternate weekly collections of household waste is investigated.

- Reducing collection frequency impacted positively on recycling rates and behaviour.

- Reducing collection frequency impacted positively on productivity and health/safety.

- No adverse impacts on environmental quality and public health were reported.

- The single stream (comingled material, 1 container) out-performed dual stream service.

Keywords: Waste management, Alternate weekly collection, Sustainability, Recycling, Local authority, Health, safety and welfare

\begin{abstract}
Residual waste is commonly collected separately from recyclable and organic materials. Different forms of collection and disposal are used internationally since regional or municipal authorities have to adapt to their own circumstances. Many authorities have adopted an alternate weekly collection (AWC) of residual waste and recyclables to force/encourage householders to recycle; however, the degree to which they achieve waste reduction has yet to be reliably quantified. This study reports on how the introduction of AWCs affects household waste arisings. The paper evaluates single and dual stream collection methods and compares their performance with the previous system.

Household waste collection trials were conducted between March and June 2009 in England (Lichfield). The trials examined changes to frequency of collection, type of container issued, amounts of sorting required of residents, household participation and productivity levels. A survey of households was completed before any changes were implemented. The quantity of recyclates collected was examined for 2008/2009 and 2009/2010.

The study showed that the AWC scheme positively impacted on recycling rates and household behaviour, with no adverse impacts on public participation, household waste arisings or the local environment. No public health problems were reported. Both trials saw an increase in the quantities of recyclates collected per household during the trial period compared to the same period of time in the previous year. The dual stream performed better than the single stream, collecting an average of $5.94 \mathrm{~kg} / \mathrm{hh} /$ week compared to an average of $5.63 \mathrm{~kg} / \mathrm{hh} / \mathrm{week}$. The single stream system showed a greater increase in the weight of material collected $(0.53 \mathrm{~kg} / \mathrm{hh} / \mathrm{week}$ vs. 0.48 $\mathrm{kg} / \mathrm{hh} /$ week). Participation and set-out rates showed an increase during the trial period. The single stream option (comingled materials in one container) outperformed the dual stream service. The reduction in costs and improved productivity were the principal reasons used for extending the trial and making changes to the district's waste collections. The study clearly demonstrates the benefits of local authorities and universities collaborating and identifies practical logistical and operational issues that need to be anticipated.
\end{abstract}

\section{Introduction}

Refuse collection from households is one of the most routine activities of governments worldwide and one that generates considerable public interest. A household waste collection service, which may be provided by either the private or public sector, is complex and requires consideration of many factors, including operational and logistical activities, provision and maintenance of appropriate equipment, provision and training of appropriate personnel, health and safety, costs, general public health and environmental issues, environmental and occupational legislation, public communication and education, recycling and composting targets, end destination facilities for residual and some organic wastes, and destinations and markets for recyclable materials. Regional and municipal authorities address these factors in many different ways and features of household waste collections vary between regions and countries. 
In many countries, especially in Europe, it is common for residual waste to be collected separately from recyclable and organic materials (such as garden and food wastes), although the collection systems used vary considerably in terms of materials collected, types of collection vessels and vehicles used, logistics and frequency of collection, and ultimate destinations for collected materials. Different forms of collection and disposal are used in various parts of a region or country since each regional or municipal authority has to adapt to its own circumstances; each has their own infrastructure, service provision and socio-economic conditions (Timlett and Williams, 2011). For example, in two-tier English authorities, household waste collection is the responsibility of Waste Collection Authorities (WCAs) - usually the District or Borough Councils - with Waste Disposal Authorities (WDAs) responsible for disposal of waste. Unitary authorities are responsible for both collection and disposal of waste. England was relatively late compared to other European countries in legislating for separate collections for residual and recyclable wastes; it was as recently as 2003 that the Household Waste Recycling Act placed a duty on English local authorities (LAs) to provide a collection of at least two types of recyclable waste from every household by 2010 unless "the cost is unreasonably high or comparable alternative arrangements are available."

Household waste Collection is an expensive public service worldwide and typically accounts for $75-80 \%$ of an authority's municipal solid waste management budget (Simonetto and Borenstein, 2007). Authorities that collect waste have limited budgets to operate their services and those that operate separate collections tend to aim for high capture of recyclates at a reasonable cost to householders. A scheme's design can have huge impact on costs, vehicle use, and amount of material collected (McLeod and Cherrett, 2008). Although Wertz (1976) found that service frequency could influence the quantities of waste collected, Kemper and Quigley (1976) found no significant relationship between the number of annual collection visits and the annual quantity of discarded waste. More modern research suggests that reducing collection frequency is a way to reduce waste collection costs that does not necessarily impact negatively on participation (Tucker et al., 2001). Fortnightly (rather than weekly) collections often mean that residents present bins each time to avoid missing a collection and struggling with the capacity they have for waste before the next collection is due (McLeod and Cherrett, 2008). However, an increased period between collections usually results in an increase in the weight of waste presented for collections (Pinder and Milnes, 2002) and therefore the increased possibility of musculoskeletal injuries to collection crew members due to moving heavier bins (McLeod and Cherrett, 2008).

Achieving a cost-effective and highly efficient dual (or multi-material) collection service requires a high percentage of residents actively participating and presenting the full range of materials accepted without any of incorrect materials. Across the globe, a number of studies have looked at different systems for collecting household waste (e.g. Huang et al., 2011; Gallardo et al., 2010; García-Sánchez, 2008; Dahlén et al., 2007; Harder and Woodard, 2007; Gellynck and Verhelst, 2007; Martin et al., 2006; Bolaane, 2006; Shaw et al., 2006; González-Torre and Adenso-Díaz, 2005; Mattsson et al., 2003; Woodard et al., 2001; Worthington and Dollery, 2001; Wang et al., 1997; Oskamp et al., 1996). Residents are typically not allowed to over-fill their wheeled bins or boxes, limiting the amount of non-recyclable waste which they can dispose and forcing them to reduce and recycle (Uzzell and Räthzel, 2009). To gain and maintain householder's cooperation, a scheme needs to be both user-and operator-friendly (Read, 1999). Simple to understand schemes with frequent collections using containers appropriate to the property's available storage space have a better chance of achieving high participation levels (Tucker et al., 2001). Convenient, simple, well explained schemes should achieve reasonable yields of recyclates and high levels of customer satisfaction. González-Torre and Adenso-Díaz (2005) reported that that the nearer containers are to citizens, the more they recycle waste. Dahlén et al. (2007) compared the different selective collection systems in use in Sweden and concluded that the quality and quantity of the recyclable materials was better when they were collected at kerbside. Gallardo et al. (2010) found that in Spanish towns and cities with populations of $>50,000$ inhabitants, four different collection systems for sorted household waste are used. They concluded that separating household waste into different fractions in situ is the most efficient way of collecting materials with the highest degree of cleanliness and quality in order to facilitate later resource recovery and, that to achieve this, it is vital to have a suitable system for selective collection at source. However, there is no standard design model that can be successfully duplicated nationally (Martin et al., 2006) or indeed, internationally. Each recycling scheme operates in its local context and takes into account situational, demographic, political and cultural factors (Timlett and Williams, 2008). This makes designing a scheme more challenging, especially with local variables such as available disposal points, amendments to existing schemes and contractual issues.

However, after careful consideration of all the variables and in a bid to reduce costs and increase the amount of waste recycled, many Las in the United Kingdom (UK) have decided to adopt an alternate weekly collection (AWC) of residual waste and recyclables, whereby the collection of material for recycling and/or composting alternates on a weekly basis with residual waste for landfill or incineration. Some LAs also operate a separate green (garden) waste collection scheme (Williams and Kelly, 2003) and separate food waste collections. In fact, the majority of the LAs in England and Wales and indeed the majority of the top performing recycling authorities in these countries operate AWCs, despite localised vociferous political opposition and a campaign by some national newspapers (e.g. the Daily Mail's "Great Bin Revolt") against its implementation. The political opposition was led by a government minister, Eric Pickles, who often used highly provocative language to convey his hostility to AWCs (e.g. the "Town Hall Taliban"; the "bin-o-crats"; "barmy bin rules have made putting out your rubbish more complicated than solving a Rubik's cube"). In 2011, Mr Pickles announced a fund of $£ 250$ million to pay councils to revert to weekly collections, which he called a "basic right" but others described as a "bribe" and a "conference stunt", but by July 2012 only one local authority (out of 251) had applied to this fund to switch back to weekly collections. The 
imposition of waste collection schemes can come at a high political price if they are not clearly explained to the public (see Uzzell and Räthzel, 2009).

Although the adoption of AWC schemes is meant to force or encourage householders to recycle, the degree to which they achieve waste reduction is hotly debated. A key benefit to a LA that adopts AWCs is that differing waste streams can be collected without large additional investment in vehicles and staff, although such schemes can be more complex to manage, explain and publicize. The relatively limited literature on this topic has shown that recyclate yields were generally higher in areas where the residual waste was being collected fortnightly rather than weekly (Chartered Institute of Waste Management (CIWM), 2004; Dixon and Williams, 2007; Wilson and Williams, 2007; Sheward and Williams, 2011; Gellynck et al., 2011). This is probably because residents are being coerced into recycling more because of the reduced collection frequency for residual waste, although it is clear that scheme design and implementation are important considerations (see for example, Dixon and Williams, 2007; Wilson and Williams, 2007; Drew et al., 2007; McLeod and Cherrett, 2008; Sheward and Williams, 2011).

In general, proponents of AWC schemes argue that providing refuse is stored in secure, rigid containers and that the scheme is carefully explained to the public, providing only one collection of residual waste each fortnight encourages people to think carefully about how they manage their waste, leading to: easier collection of waste, increased waste minimisation, reuse and recycling; reduced collection, disposal and transportation costs; reduced transport emissions; regional and municipal authorities meeting their statutory requirements and countries meeting their legal obligations under the Landfill Directive. Adversaries of AWC maintain that leaving refuse uncollected for a fortnight is unpopular amongst householders; unhygienic; attracts vermin, flies and maggots; and leads to increased fly-tipping. However, there is no evidence to support these claims other than for fly-tipping (Hodsman and Williams, 2011), and this may be coincidental rather than as a direct result of the introduction of AWC schemes. Opponents also argue that because recycling is voluntary within the UK, householders will be unlikely to participate effectively if they are not satisfied with the service provided. From an occupational health perspective, a related and ongoing debate about the relative risks to workers of musculoskeletal injuries from the manual handling of waste containers is unresolved, although there is evidence that the use of wheeled bins reduces the risk of injury (e.g. Oxley et al., 2006).

Understanding what influences recycling behaviour has been seen as key to increasing participation and thus affecting waste management behaviour. However, there has been little research into how implementing systems such as AWCs can impact directly on those factors that affect recycling and waste minimisation behaviour and ultimately the amount of waste generated.

This detailed study, based in a borough in the midlands of England (Lichfield), reports on how the introduction of AWCs can affect household waste arisings. The paper evaluates two different collection methods and compares their performance with the previous kerbside collection system. The main objectives were to:

- Critically explore the extent to which household waste arisings changed within the district since the introduction of an AWC

- $\quad$ scheme.

- Critically examine householders' attitudes and behaviour change since the AWC introduction, exploring if and how it links to changes in waste arisings.

- Quantify productivity levels for the three different collection methods.

- Identify any logistical problems that might arise if the LA changed the kerbside collection across the entire district.

- Using experience gained from the trial to formulate an action plan for a full service change to the option that provided best value for the local population, having evaluated costs, service levels recycling performance and public acceptance and tested communications material.

\section{Historical context}

Lichfield District Council (LDC) is a WCA in the south of the county of Staffordshire (Fig. 1), responsible for collecting the waste from a population of 93,000 people in 42,000 households. Lichfield is a rural district with a population density averaging 2.80 people hectare-2; the national average is 3.77 people hectare-2. There are no major industries sited within Lichfield District and consequently many people commute out of the area to work. In addition, there is no large university, so the district does not have a significant transient population.

Since 2002/03, the authority has operated weekly collections of comingled dry recyclates alongside fortnightly collections of organic waste (food and garden waste) and residual waste (black bin). The organic waste is delivered to two local in-vessel composting sites, enabling the authority to comply with the Animal By-Products Regulations (2003). Weekly kerbside collections of recyclates used two green boxes, one for paper and cardboard and the other box for glass bottles and jars, steel and aluminium cans and mixed plastics. Recyclates from Lichfield's kerbside collections are taken to a Materials Recovery Facility (MRF) and the residual waste is taken to landfill; in 2008/09 Lichfield District Council delivered a total of 23,352.28 tonnes of household waste to landfill sites. Additional materials have been added to the recycling and composting collections; food waste was added to garden waste collections in August 2007 and mixed plastics added to dry recycling collections in June 2008. 
Lichfield's contract with the MRF operator offered the option of delivering recyclates into the MRF fully comingled (all recyclates mixed together) or dual stream (glass, cans \& mixed plastics collected separately from paper and cardboard). This meant that Lichfield could deliver recyclates source separated (either by residents or collection crews using kerbside sort collection vehicles) and provided an opportunity to establish if there were any benefits in changing to a comingled collection, or if a reduced frequency collection similar to the existing scheme would be better suited to its circumstances. The trial also enabled an evaluation of the costs of both collection methods.

LDC has consistently been amongst the top 20 performing WCAs since 2000 , reporting figures above $42 \%$ each year for the total percentage of household waste collected that is sent for recycling and composting. LDC was the highest performing LA in England and Wales in 2002/03 and achieved Beacon Council Status ${ }^{1}$ for Waste Management in 2006. However, despite this relatively successful performance, there were some problems with the collection service (listed below), and these prompted the introduction of a new scheme:

- The boxes used for the kerbside collection of recyclables did not have lids and were blamed for litter that appeared after collection

- days.

- $\quad$ Some elderly people found boxes difficult to manage.

- There are significant manual handling issues for both crews and residents when boxes are full, and the contents get wet, making them heavier.

- $\quad$ Large families and very keen recyclers reported that 2 boxes were not enough, so they have additional boxes, present recycling on

- $\quad$ the kerbside in carrier bags, or do not recycle all the items they could.

- Empty boxes regularly went missing; on windy days empty boxes were often blown away, never to be seen again. In 2009, 800 sets

- $\quad(1600$ individual) lost or missing boxes were replaced by LDC at a cost of $£ 4000$. This is in contrast to the 25 wheeled bins (total value £500) that needed to be replaced during the same time period.

- $\quad$ Lichfield has a historic city centre, with the road layout and some properties dating back to Tudor ${ }^{2}$ times. $^{2}$ Many properties within the city have no outside storage and are in a conservation area, ${ }^{3}$ restricting alterations that can be made to properties. Such properties are not suitable for collections using a wheeled bin due to storage or access problems. Lichfield has always offered special collection services to properties unsuitable for general collection rounds. Many of these households are served by a smaller vehicle, often on weekly refuse collections using bags.

\section{Methods}

\subsection{Household waste collection trials}

Collection trials operated in three villages between March 2009 and June 2009. The villages of Armitage and Handsacre together form the parish of Armitage with Handsacre; this parish had a population of 5181 recorded in the 2001 Census. The neighbouring village of Kings Bromley had a population of 1651 recorded in the 2001 Census. The villages are to the North of Lichfield (Fig. 1). Statistical information on income, employment, education, housing, environment and crime for English local authority areas was obtained from the index of multiple deprivation (IMD). The IMD describes small population groups in Lower super output areas (LSOAs); these generally contain 1500-3000 people. Studying groups of this size gives more detail than researching a whole ward. England has 32,482 LSOAs which are ranked nationally; with positions allocated between 1 and 32,482. Position 1 is the most deprived LSOA in the UK and 32,482 is the least deprived LSOA in the UK.

There were four LSOAs covered by the recycling trials; three in Armitage with Handsacre and one in Kings Bromley; their national IMD rankings are shown in Table 1. One area of Armitage and Handsacre is roughly comparable with Kings Bromley and the other two areas in the Armitage and Handsacre ward are similar to each other. These villages were seen to be representative of the district, with no distinct features to single them out from any of the other areas in the district. Both trial areas have a variety of different property types ranging from large detached properties to smaller semidetached houses built quite close to each other. There were no high-rise properties in the areas chosen for the trials; this is typical of Lichfield District. There were some older terraced properties with no front gardens and some modern apartment blocks that have communal bins within bin stores. These properties were excluded from the trial.

The trials, summarised in Table 2, examined changes to frequency of collection, type of container issued, and the amount of sorting required of residents. Both trials involved a reduction in collection frequency from weekly to fortnightly collections, with no change to collection days. There was no change in the number or type of materials collected from households. Each trial collected the same range of materials as the existing collections; however, in one trial there was a change in the amount of sorting residents were asked to execute. In Trial $A$, residents were

\footnotetext{
${ }^{1}$ Local authorities judged to be models of excellence and able to demonstrate their exemplary practices in a specialist area of work are awarded "Beacon" status by government

2 The Tudor period refers to the period between 1485 and 1603 that corresponds with the rule of the Tudor dynasty in England

${ }^{3}$ An area considered worthy of preservation or enhancement because of its special architectural or historic interest
} 
required to place all recyclates into a 240 -litre wheeled bin and the recycling boxes were removed from these properties. An existing recycling collection round had to be changed to enable easier tracking of tonnages and hours worked for comparison and monitoring purposes. In Trial B, residents placed glass, steel and aluminium cans, and mixed plastics in a 240-litre wheeled bin and used the existing recycling boxes for paper and cardboard. When collected, paper and cardboard are treated together. At the collection point, the 2 items were separated (as shown in Table 2) as it was thought that a 55-litre box full of paper (particularly if wet on rainy days) would be too heavy for operatives and the public to lift. Operatives placed all materials into a single compartment on a collection vehicle in Trial A properties whilst in of Kings Bromley had a population of 1651 recorded in the 2001 Census. The villages are to the North of Lichfield (Fig. 1). Statistical information on income, employment, education, housing, environment and crime for English local authority areas was obtained from the index of multiple deprivation (IMD). The IMD describes small population groups in Lower super output areas (LSOAs); these generally contain 15003000 people. Studying groups of this size gives more detail than researching a whole ward. England has 32,482 LSOAs which are ranked nationally; with positions allocated between 1 and 32,482. Position 1 is the most deprived LSOA in the UK and 32,482 is the least deprived LSOA in the UK. There were four LSOAs covered by the recycling trials; three in Armitage with Handsacre and one in Kings Bromley; their national IMD rankings are shown in Table 1. One area of Armitage and Handsacre is roughly comparable with Kings Bromley and the other two areas in the Armitage and Handsacre ward are similar to each other. These villages were seen to be representative of the district, with no distinct features to single them out from any of the other areas in the district. Both trial areas have a variety of different property types ranging from large detached properties to smaller semidetached houses built quite close to each other. There were no high-rise properties in the areas chosen for the trials; this is typical of Lichfield District. There were some older terraced properties with no front gardens and some modern apartment blocks that have communal bins within bin stores. These properties were excluded from the trial. The trials, summarised in Table 2, examined changes to frequency of collection, type of container issued, and the amount of sorting required of residents. Both trials involved a reduction in collection frequency from weekly to fortnightly collections, with no change to collection days. There was no change in the number or type of materials collected from households. Each trial collected the same range of materials as the existing collections; however, in one trial there was a change in the amount of sorting residents were asked to execute. In Trial A, residents were required to place all recyclates into a 240 -litre wheeled bin and the recycling boxes were removed from these properties. An existing recycling collection round had to be changed to enable easier tracking of tonnages and hours worked for comparison and monitoring purposes. In Trial B, residents placed glass, steel and aluminium cans, and mixed plastics in a 240-litre wheeled bin and used the existing recycling boxes for paper and cardboard. When collected, paper and cardboard are treated together. At the collection point, the 2 items were separated (as shown in Table 2) as it was thought that a 55-litre box full of paper (particularly if wet on rainy days) would be too heavy for operatives and the public to lift. Operatives placed all materials into a single compartment on a collection vehicle in Trial A properties whilst in Trial B the partly sorted materials were amassed in a vehicle that enabled two material streams to be collected separately by one vehicle.

LDC operates its own in-house fleet of waste collection vehicles and the trials were organised to fit in with existing collection rounds. At the time, the authority had 8 collection vehicles for recyclates, 7 of which were split-bodied vehicles that allow a dual stream kerbside collection. The remaining vehicle was a caged tipper vehicle, used to service remote and difficult to access properties.

Two existing collection rounds were chosen for the trials. Both rounds had similar travelling distances from the depot and disposal sites. Friday collections were chosen because collection vehicles are traditionally emptied before returning to the depot on Friday afternoons. The trial collection vehicles were emptied in the morning before collections commenced to facilitate recording of accurate figures on the amount of material collected. One round became the single stream (Trial A) round without any changes to the number of properties. This round collected from 1175 properties in the villages of Armitage and Handsacre. The dual stream round (Trial B) in Handsacre and Kings Bromley was adapted from an existing collection round. It was anticipated that Trial B would take longer to complete, therefore the number of properties on the round was reduced to 975 properties ensuring rounds would be completed within a working day.

\subsection{Monitoring participation and set-out rates}

The collection rounds chosen for the trials were monitored on collection days for four successive weeks to quantify the number of households participating in the collection service. The monitoring was carried out by the collection crew, counting the containers presented for collection. This was found to be the most accurate way of collecting this data because some people put their containers out just prior to collection and some containers are removed from the kerbside as soon as they have been emptied. Properties presenting materials for collection at least once during the monitoring period were counted as participating. For the purpose of this study, the weekly green box recycling collections were monitored for a period of four weeks (four collections) prior to any announcement about the trial being made to residents. The same households were also monitored once the fortnightly trial collections were established; the monitoring took place over a 4-week period (2 collections). Information gathered enabled a set-out ratio (\%) to be calculated for each of the trials; using the set-out ratio as defined by the CIWM (2004). Setout rates and participation levels were examined to highlight any change in the number of households using the collection service. 


\subsection{Social survey}

A questionnaire was issued to households on both trials before any changes were implemented. The survey obtained quantitative data from householders using a range of open and closed questions. The purpose of the survey was to determine satisfaction levels with existing recycling and organic waste kerbside collections, establish how often they used the kerbside collections, evaluate the suitability of the green plastic boxes for storage and collection of recyclates and investigate whether respondents found the collections "easy to understand". The survey was delivered to every third house along the collection routes, giving a representative sample of property types across council tax bands. Questionnaires were hand delivered to 419 of the 1175 properties on the single stream trial (Trial A) on 4th, 5th and 6th March 2009 and to 316 of the 975 properties on the dual stream trial (Trial B) on 12th and 13th March 2009. This approach was chosen to keep costs down and to enable the survey to be easily distributed (Read et al., 2009).

Completed questionnaires were collected from Trial A on 7th and 8th March 2009 and Trial B on 14th and 15th March 2009. Surveys were collected soon after delivery to increase the response rate because it is recognised that surveys that rely on self-administered questionnaires usually have a low return rate.

\subsection{Analysis of weighbridge tickets}

Waste collection vehicles are issued with weighbridge tickets showing the weight of waste material (organic waste, recyclates or residual waste) deposited at disposal sites. WCAs record and report the weight (tonnes) of all waste streams collected to the relevant government department via WasteDataFlow (2007), a web-based reporting system, allowing performance monitoring.

Figures entered onto the system are subjected to external audit. WasteDataFlow information for the 20-week period between 20 March and 7 August in both 2008 and 2009 for the trial areas was examined to identify any trends before and during the trials. The 2008 data was studied to enable comparison unaffected by seasonal changes to recycling collections (such as extra weights at Christmas, Bank Holidays and during school holidays).

No communications work was undertaken on either collection round during 2008 , other than the delivery of annual calendars showing collection dates. In 2009, new wheeled bins were delivered to properties during early March with leaflets explaining the changes to collections, reduction in frequency and amendments sorting carried out by householders. Information differed slightly between trials, but the same amount of communication work was carried out in each trial area.

The quantity of recyclates collected in the trial areas was examined for both 2008/2009 and 2009/2010 to establish if there was any increase or decrease in the weight of material collected during the trials and to determine if either trial captured more recyclates. WasteDataFlow records for residual waste collected in the trial areas and taken to landfill sites was examined for the years 2008/2009 and 2009/2010, primarily to see if there was any increase or decrease in residual waste collected in the trial areas.

\subsection{Timesheet analysis}

Collection crews at LDC work on a "task and finish" basis, going home once the day's work is finished. Hours worked by each crew is managed monthly to ensure they are not widely out of line with each other. Each crew's daily hours are entered onto a timesheet, both for the payroll system and to ensure that employees are working within the relevant legislation regarding working practices (The Working Time (Amendment) Regulations, 2003) and driver's hours (The Road Transport (Working Time) Regulations, 2005).

Time sheets were examined for both trial collection rounds for the period of the trials in 2009 to ascertain productivity levels for the trials. Using data collected on hours worked by collection crews it is possible to calculate productivity measures such as kilogrammes of waste collected per household per hours worked and also number of properties that are serviced per hour. It had been the intention to also look at staff sickness records in the same way, but there had been some change of staff during the 12 months prior to the trial and it was considered that due to lack of consistency that this would not serve any useful purpose.

\subsection{Limitations of the trials and the methods employed}

All field experiments have site-specific, resource, operational or practical limitations, and in order to properly contextualise the results, it is good practice for them to be outlined. Data collected occurred for a relatively short period of time ( 10 collection days over a period of 20 weeks) and only covered two of the WCA's 37 collection rounds. Whilst these two collection rounds appear to have residents and properties that are representative of Lichfield District, they may not be representative of other areas in the UK.

The WCA took action to ensure vehicles collecting recyclates during the trials were empty before they started the collection rounds and that they were emptied before being used again. This ensured that the weight of materials recorder for the trials was accurate. The same measures were taken with the residual waste on those two collection rounds during the trial. It had not been possible to ensure this took place with the collections the previous year and hence the 2008 data may not always be completely accurate. 
The reported figures for recyclates do not take into account levels of contamination (materials that are not collected for recycling or should not be included in the collection). The MRF operator declared a $4 \%$ contamination rate and this figure was reported to the relevant government department via WasteDataFlow as the contamination level in LDC's recyclate collections for 2009/10.

\section{Results}

\subsection{Monitoring participation and set-out rates}

Collection crews monitored participation in kerbside recyclate collections for 4 successive weeks. Properties presenting material for collection once during the monitoring period were counted as participating. Monitoring took place pre-trial and three months after the start date. The results of the monitoring are shown in Table 3. Participation levels increased on both trial rounds during the observation period; the increase was greater in the dual stream trial than the single stream trial.

\subsection{Household waste collection trials}

Weights of recyclates collected on Friday's recycling Round 2 between 20March and 7 August 2008 are shown in Fig. 2 (20 collections). This round became Trial A in 2009. The average weekly weight collected was 5.92 tonnes, giving an average weight of recyclates collected of $5.04 \mathrm{~kg}$ per household per week $(\mathrm{kg} / \mathrm{hh} / \mathrm{week})$.

In 2009, the frequency of kerbside collections changed from weekly to fortnightly. Collection crews deposited recyclates twice each collection day. Daily total collection weights were calculated for each trial area by adding weights of materials collected on the same day together. The single stream collection crew collected recyclates fortnightly from 20 March 2009. The daily total weights of recyclates for the 10 collections during the trial period are shown in Fig. 3. The average weight of recyclates collected was 12.95 tonnes per fortnight; this equates to an average weight of $5.51 \mathrm{~kg} / \mathrm{hh} /$ week.

Weights of recyclates collected on Friday's recycling Round 3 between 20 March and 7 August 2008 are shown in Fig. 4 (20 collections). This became Trial B in 2009. The average weekly weight of recyclates was 6.28 tonnes, giving an average weight of recyclates collected of $5.46 \mathrm{~kg} / \mathrm{hh} /$ week. The dual stream collection crew collected recyclates fortnightly from 27 March 2009. The daily total weights of recyclates for the 10 collections during the trial period are shown in Fig. 5. The average weight for recyclates collected on this trial was 11.58 tonnes per fortnight, or 5.51 tonnes per week; this was from 975 properties and equates to an average weight of recyclates of 5.65 $\mathrm{kg} / \mathrm{hh} /$ week.

The daily total weight of recyclates collected from both trial areas on the first 10 trial collection dates was examined to establish which trial, if any, collected the most material during the course of the trials.

It appears that the single stream trial, Trial A, outperformed the dual stream trial, Trial B. However, Trial A collected materials from 1175 properties and Trial B collected from 975 properties. Therefore, the weight of material collected per household was calculated allowing comparison of the two trial's performance. The calculation used was:

\section{Daily total weight of recyclate collected on the round}

Number of properties on the collection round:

The results are shown in Table 4. On collection weeks one, two and five the single stream trial collected more recyclates per household than the dual stream trial. The dual stream system outperformed the comingled single stream system over the remainder of the collection weeks, consistently collecting more recyclates per week per household. The average weekly weight of recyclates collected per household over the 20-week period was calculated for both trials from the total weight of material collected. During the period studied, the dual stream performed better than the single stream, collecting an average weight of $5.94 \mathrm{~kg} / \mathrm{hh} /$ week compared to an average of $5.63 \mathrm{~kg} / \mathrm{hh} /$ week. However, the single stream system showed a greater increase per household in the weight of material collected $(0.53 \mathrm{~kg} / \mathrm{hh} /$ week compared to $0.48 \mathrm{~kg} / \mathrm{hh} /$ week $)$.

The weight of recyclates collected fortnightly per household was calculated for the 20-week period (20 March7August) in both 2008 and 2009 for both trial areas. The calculated figures for 2008 were compared to the fortnightly collection figures obtained during the 2009 trials; the results for Round 2, the single stream area is shown in Table 5 . The fully comingled single stream trial collected more recyclates per household than the 2008 dual stream weekly box collections on Round 2 on 9 of the 10 collections. The same properties were used in both years; changes made to the collections were a reduction in frequency of collections, amendment to the amount of sorting carried out by the householder and larger containers provided by the Waste Collection Authority.

The results for Round 3 are shown in Table 6 . The dual stream trial collected more recyclates per household than the 2008 weekly box collections on 8 out of 10 collection dates and an identical amount was collected in both 2008 and 2009 on one collection day. The collection frequency was reduced in this trial area from weekly to fortnightly. The amount of sorting carried out by the householder remained the same and a larger container was provided to each household.

The costs of the trials were not accounted for separately although some data were obtained. There was a one-off cost of $£ 20$ per property for new wheeled bins (total £43,000). The printing of information leaflets was relatively 
small and absorbed into corporate printing costs. A reduction in service costs due to the switch from weekly to fortnightly collections produced savings on fuel and labour costs that balanced out the additional labour costs for longer working days. The vehicles used on the single stream trial had a payload of 10 tonnes whilst the vehicles used for dual stream collections had a payload of 7.5 tonnes. The larger vehicles required emptying less often and therefore made fewer visits to the MRF - this created a reduction in fuel costs (although this was not quantified). In addition to their smaller payload, the "twinpack" vehicles for collecting dual stream materials were more expensive to purchase, maintain and operate and had lower fuel efficiencies. Consequently, changing from a "twinpack" to a standard collection vehicle created savings for each "twinpack" removed from the fleet.

The gate fees at the MRF changed due to the additional sorting that was required. The dual stream collections with paper and cardboard kept separately generated an income of $£ 10$ per tonne whilst the single stream collections attracted a gate fee that cost $£ 5$ per tonne. The increase in fees for sorting at the MRF was balanced by the reduction in costs for labour, fuel and vehicles (outlined above).

\subsection{Landfill of household waste}

Residual waste was collected fortnightly from households in Lichfield District. Weighbridge tickets issued at landfill sites for Friday Rounds 2 \& 3 in 2008 and the trial rounds in 2009 were analysed for the 20 -week period 20 March8 August. Collection crews frequently visited the landfill site twice on the Friday collection rounds, when this happened weighbridge tickets issued on the same day for a collection round were added together to give a daily total for that collection round. In 2008, Round 2 collected residual waste from 1175 properties and Round 3 collected residual waste from 1150 properties. The number of properties on the residual waste collection rounds was unchanged for the trial period.

The average daily total weights of residual waste per collection period in 2008 and 2009 are shown in Table 7 for Trial A and Table 8 for Trial B. The overall average daily weights of residual waste per collection day and per household are summarised in Table 9. There was a reduction in the amount of residual waste collected in both trials in 2009 compared to the amount collected in 2008.

\subsection{Social survey}

The pre-trial survey was delivered to 419 properties on the single stream trial and 180 completed questionnaires were returned, a $42 \%$ response rate. The survey was delivered to 316 properties on the dual stream rounds, with 104 completed questionnaires, a $33 \%$ response rate. Overall $92 \%$ and $95 \%$ of respondents reported they were "very" or "fairly" satisfied with the kerbside recycling and food/garden waste collections, respectively. Overall, $72 \%$ of respondents reported that they could fit all their recyclates into their boxes; $88 \%$ reported that they presented boxes for collection every week and $83 \%$ felt the existing scheme was easy to understand.

\subsection{Timesheet analysis}

The collection crews' working hours were monitored using timesheets during the trial period (Table 10). Both trials commenced with a collection vehicle and a three-man crew. The single stream trial was easier for the operatives, emptying only a container (a 240-litre wheeled bin) at each property. Although the dual stream trial collected from 200 fewer properties, it had been expected to take longer to complete this collection round with three containers at each property. In fact, it took considerably longer than expected to complete the dual stream collections and from the 4th week of trials, an additional vehicle and two-man crew were added to this round. The dual stream system now had two vehicles and five men working on the collection round.

The crew on the single stream round worked longer hours than they had before the trial. They were collecting material from the same households as they had been pre-trial, but with the frequency of collections reduced to fortnightly, they were now collecting more material and visiting the disposal site twice each collection day, compared to once a day before the trials. To produce a measure of productivity, the total weight of recyclable material collected on each round was divided by the total number of hours worked on that collection round for each week of the trial. This gave a weight of recyclates collected per working hour; these are shown in Table 11. Over the trial period, the crew on the single stream collection system collected an average of $117.33 \mathrm{~kg} / \mathrm{h}$ more than the crew on the dual stream system.

As an additional measure of productivity, the number of properties visited per hour was calculated for both collection rounds. The crew on the single stream trial visited $70-81$ properties/h/week and crew on the dual stream trial visited 39-41 properties/h/week.

\section{Discussion}

The survey results showed very high levels of public satisfaction and Engagement with the waste management services provided by Lichfield District Council prior to the commencement of the trials. Reported satisfaction compared favourably with the Place Survey (2008), which recorded a $70 \%$ satisfaction figure for doorstep recycling collections nationally and an $84 \%$ satisfaction figure for Lichfield, the fourth highest score for an individual local authority (DCLG, 2009). Most respondents claimed to participate fortnightly or weekly in collection schemes; this matched set-out rate figures calculated from participation monitoring carried out before the trials started (at the same time as the households were surveyed). However, it is recognised that self-reporting of participation is often higher than actual participation in behaviours like recycling (Timlett and Williams, 2008). There has been no longterm monitoring to establish the accuracy of this claimed participation. 
Eighty-three percent of respondents said the scheme was "easy to understand" and this may explain the high levels of performance achieved by LDC's recycling collection service. However, there is room for improvement. Single stream, comingled collections may to be easier to understand with householders expected to perform less segregation of materials.

The introduction of an AWC scheme into Lichfield did not have any adverse effects on public participation, household waste arisings or the local environment and no public health problems were reported to the local authority during the trial period. High levels of participation were recorded before and during the trials, probably because the kerbside collection service has been in existence for several years. Studies show existing recyclers are most likely to support new recycling schemes (Burnley and Parfitt, 2000). The study suggests that adopting either of the trial collection methods would result in an increase in participation and set out rates, assisting the LA to meet statutory targets for landfill diversion and recycling. It is worth noting that contamination was not investigated and that the social survey suggested that some householders only recycled the amount their boxes held, subsequently putting additional recyclates in the residual waste container.

Regardless of collection method, the introduction of an AWC scheme clearly resulted in an increase in the amount of recyclates collected from households. The weight of recyclates collected on Trial A increased from 5.10 $\mathrm{kg} / \mathrm{hh} /$ week to $5.5 \mathrm{~kg} / \mathrm{hh} /$ week; if this figure was sustained it would result in an increase of $27.0 \mathrm{~kg} / \mathrm{hh} / \mathrm{year}$. The weight of recyclables collected on Trial B increased from $5.46 \mathrm{~kg} / \mathrm{hh} /$ week to $5.94 \mathrm{~kg} / \mathrm{hh} /$ week; again, if this figure was sustained it would result in an increase of $49.8 \mathrm{~kg} / \mathrm{hh} /$ year. If these systems were employed throughout Lichfield District, the projected annual increase in collected recyclables would be significant; 1134 and 2092 tonnes, respectively, from Trial $A$ and $B$ systems. In addition, there was a reduction in residual waste collected in both trial areas over the 10 collection dates in 2009 when the AWC was implemented, compared to the same weeks in 2008. However, whilst the changes to the collection frequency and containers may have had some effect on the amounts of dry recyclates and residual waste gathered, other external factors need to be considered. The serious downturn in the global economy that has been experienced since 2008 almost certainly impacted on the amount of waste generated within a household, with householders behaving in a more sustainable way, wasting less food, replacing consumable products less often and buying and selling second-hand items instead of disposing of them as waste. Work undertaken by manufacturers and retailers under the Courtauld Commitment (WRAP, 2010) to reduce the amount of packaging waste following the introduction of the Packaging Essential Requirements Regulations, 2003 and the Producer Responsibility Obligations (Packaging Waste) Regulations, 2007 may have also had some impact on the waste generated within households.

The waste management service cost LDC $£ 70,000$ less than in $2008 / 9$. In addition, the move to the AWC system resulted in a reduction of transport and employee costs of $£ 68,000$ compared to $2008 / 9$. Further cost savings were achieved as the introduction of the AWC system resulted in 3 vehicles being removed from service. Following the success of the AWC trials, LDC introduced single stream comingled fortnightly collection of recyclable materials in September and October 2010. Although the projections outlined above were not subsequently fully attained, partially because of the effects of the global economic downturn on households' purchasing power and the rapid rise in fuel prices, substantial savings and productivity benefits were still realized. LDC's system savings based on experience of full AWC service 3/11/09 to 22/01/10 were 16,000 km in reduced vehicle mileage (and consequent reduction in vehicle emissions, an increase in recycling tonnages of 489 , and a reduction in residual tonnages of 181). In a full year, LDC's service anticipated savings of $£ 97,000$. In addition, the WDA (Staffordshire County Council) would have reaped savings of $£ 7240$ from reduced Landfill Tax.

On both calculated measures of productivity, the single stream trial performed significantly better than the dual stream trial (Table 12). The dual stream approach was not popular with the collection crews and was more labour intensive. The crews found the dual stream approach presented them with significantly more work as they were visiting the boundary of each property twice to empty three containers. They also found it difficult to get into a smooth pattern of working, emptying boxes into one side of the rear of the vehicle and a bin on the other side of the vehicle. They often got in each other's way. Unsafe practices were evident, for example trying to carry two boxes at the same time as wheeling a bin and also trying to stack full boxes on top of the bin whilst moving it to the vehicle. Health and Safety briefings were carried out to stop this practice. In England, each WCA receives "Recycling Credits" payments from the WDA; this is currently $£ 40.80$ per tonne (2010/11). This payment is made in recognition of savings on disposal costs made by the WDA by the diversion of waste from landfill. It is possible that the higher annual yield of recyclates combined with the subsequent increase in the Recycling Credit payment from the WDA and the lower gate fee payable at the MRF would cover the cost of the additional staff required to operate dual stream collections.

Logistical and operational issues that need to be anticipated and planned for include: consideration of lease periods for collection vehicles; potential for equipment modifications to collection vehicles; allowance of an appropriate "roll out" period for a new service (e.g. delivery of new bins, removal of old boxes (where residents didn't want to keep them), site visits to dissatisfied residents or those who may require a specialised service, communications work leaflets, press releases, interviews on local radio stations); and development of an appropriate contingency plan in the event of e.g. delivery problems or emergencies. It is also worth anticipating and planning for likely complaints from a vociferous minority of residents who don't like change or who may have a political reason for disliking the 
new system; in Lichfield complaints included dislike of the new bin's colour and criticism of increased storage capacity. It is recommended from experience that complainants should always receive a site visit and solutions are nearly always easily found e.g. by issuing smaller 140 litre bins (for recyclates and residuals) and allowing neighbours sharing bins (elderly people living alone with neighbour in similar circumstances).

\section{Conclusions}

The study has clearly shown that the adoption of an AWC scheme has positively impacted on recycling rates and household behaviour, with no obvious adverse impacts on public participation, household waste arisings or the local environment. No public health problems were reported. Reducing the frequency of collections did not have a negative impact on the yield of recyclates collected; both of the trials saw an increase in the amount of recyclates collected per household during the trial period compared to the same period of time in the previous year. Participation and set-out rates were monitored, and productivity levels were investigated, these also showed an increase during the trial period.

This study has shown that focussing solely on one part of a waste service provides slightly different conclusions about which is the "better" collection method. If obtaining maximum yield of recyclates is the primary concern, then the Trial B system (dual stream option) would be the choice to opt for. This collection method consistently outperformed Trial A (single stream), showing these residents were willing and capable of sorting material into several different containers if they are issued with large enough containers and have the room for storage. However, the trials showed that the single stream option (comingled materials in one container) was:

- $\quad$ Significantly cheaper in terms of vehicle and staffing costs.

- Far easier for the crew to manage operationally.

- Far better in terms of the different measures of productivity determined.

- Beneficial in terms of the health, safety and welfare of the collection crews. The use of one wheeled bin per property greatly reduced manual handling issues that are faced when collection service uses boxes for the storage and presentation of recyclates. The number of properties that were visited per hour was also greater with the single stream collections and this means that during busy periods of the day crews can be out of the way of traffic far quicker, reducing the possibilities of traffic accidents on collection days. This is a highly significant conclusion given that accident rates in the waste industry have been reported as four times the UK national average and that collection activities account for the majority (75 to $80 \%)$ of accidents (HSE, 2012).

- $\quad$ Easier for residents to understand. Information for residents was far easier to produce for the single stream collections than the dual stream collections. There was a simpler message, less room for confusion and the leaflets were "less cluttered" with instructions about sorting materials and presentation of containers for collection.

The study concentrated on kerbside collections of recyclates from the WCA's viewpoint. A more holistic approach which included consideration of obligations currently assigned to the WDA and issues of contamination and quality of material collected would provide a broader perspective. Further research is recommended to establish if the increased yield of recyclates is maintained long term or is a result of the renewal of information and interest generated by the delivery of new containers. Further research is also recommended to quantify the cost of collection and disposal for both collection methods. This should take into account the difference in the gate fees charged by the MRF dependant on the levels of sorting the material being deposited has undergone. Single stream comingled materials attract a higher gate fee than the dual stream materials where the paper and cardboard has been kept separate.

Following the success of the AWC roll-out, LDC introduced single stream comingled fortnightly collection of recyclable materials in September and October 2010. Feedback since the system was extended across the whole of Lichfield District has been overwhelmingly positive. Despite national, minister-led political pressure to revert to weekly collections, LDC (and a number of other authorities) remains committed to the AWC system based upon its obvious, evidenced success. The study has further illustrated the benefits of local authorities and universities working together in partnership based on the principles outlined by Williams (2009).

\section{Acknowledgements}

The authors would like to acknowledge the assistance and contributions of colleagues at Lichfield District Council, particularly Ruth Plant and Tony Harris, and the residents of the Borough.

References

Bolaane B. Constraints to promoting people centred approaches in recycling. Habitat Int 2006; 30:731-40.

Burnley S, Parfitt J. Public attitudes to waste and waste management. UK: Dept of Environmental and Mechanical Engineering, The Open University; 2000.

Chartered Institute of Waste Management (CIWM). Kerbside collection of recyclables and compostable waste. Northampton, UK: CIWM, ISBN: 0-902944-55-X; 2004.

Dahlén L, Vukicevic S, Meijer JE, Lagerkvist A. Comparison of different collection systems for sorted household waste in Sweden. Waste Manage 2007; 27:1298-305.

Department for Communities and Local Government (DCLG). Available at: http://www.communities.gov.uk/documents/statistics/xls/1326148.xls 2009. [date of last access 07/07/2012]. 
Dixon J, Williams ID. The Recycling4Fylde initiative. Commun Waste Resour Manage1754- 5714 2007;8(1):3340.

Drew G, Tamer A, Hough R, Chackiath S, Longhurst P, Broomfield M, et al. Health Impact assessment of alternate week waste collections of biodegradable waste. Report number DE0110102A. Sitka Drive, Shrewsbury SY2 6LG: Enviros Consulting Ltd, Enviros House; 2007.

Gallardo A, Bovea MD, Colomer FJ, Prades M, Carlos M. Comparison of different collection systems for sorted household waste in Spain. Waste Manage 2010; 30:2430-9.

Garcia-Sanchez IM. The performance of Spanish solid waste collection. Waste Manage Res 2008;26(4):327-36. Gellynck X, Verhelst P. Assessing instruments for mixed household solid waste collection services in the Flemish region of Belgium. Resour Conserv Recycl 2007;49(4): 372-87.

Gellynck X, Jacobsen R, Verhelst P. Identifying the key factors in increasing recycling and reducing residual household waste: a case study of the Flemish region of Belgium. J Environ Manage 2011; 92:2683-90.

González-Torre PL, Adenso-Díaz B. Influence of distance on the motivation and frequency of household recycling. Waste Manage 2005; 25:15-23.

Harder MK, Woodard R. Systematic studies of shop and leisure voucher incentives for household recycling. Resour Conserv Recycl 2007; 51:732-53.

Health, Safety Executive (HSE). Health and safety statistics in waste management and recycling. Available at: http://www.hse.gov.uk/waste/statistics.htm 2012. [date of last access 07/07/2012].

Hodsman C, Williams ID. Drivers for the fly-tipping of household bulky waste in England. Municipal engineer, 164 (Issue ME1); 2011. p. 33-44.

Huang Y-T, Pan T-C, Kao J-J. Performance assessment for municipal solid waste collection in Taiwan. J Environ Manage 2011; 92:1277-83.

Kemper P, Quigley JM. The economics of refuse collection. Ballinger Pub. Co.; Cambridge, Mass.: 1976 [ISBN 0884106047].

Martin M, Williams ID, Clark M. Social, cultural and structural influences on household waste recycling: a case study. Resour Conserv Recycl 2006;48(4):357-95.

Mattsson $\mathrm{CH}$, Berg PEO, Clarkson PA. The development of systems for property close collection of recyclables: experiences from Sweden and England. Resour Conserv Recycl 2003; 38:39-57.

McLeod F, Cherrett T. Quantifying the transport impacts of domestic waste collection strategies. Waste Manage 2008;28(11):2271-8.

Oskamp S, Zelezny L, Schultz PW, Hurin S, Burkhardt R. Commingled versus separated curbside recycling: does sorting matter? Environ Behav 1996;28(1):73-91.

Oxley L, Pinder ADJ, Cope MT. Manual handling in kerbside collections and sorting of recyclables (HSL/2006/25). Buxton, UK: Health \& Safety Laboratory; 2006.

Pinder ADJ, Milnes E. Manual handling in refuse collection, HSL/2002/21. Available at: http://www.hse.gov.uk/research/hsl_pdf/2002/hsl02-21.pdf 2002. [Accessed 01/05/12].

Read AD. "A weekly doorstep recycling collection, I had no idea we could!" Overcoming the local barriers to participation. Resour Conserv Recycl 1999;26(3-4):217-49.

Read M, Gregory MK, Phillips PS. An evaluation of methods of four key methods for monitoring household waste prevention campaigns in the UK. Resour Conserv Recycl 2009;54(1):9-20.

Shaw PJ, Lyas JK, Hudson MD. Quantitative analysis of recyclable materials composition: tools to support decision making in kerbside recycling. Resour Conserv Recycl 2006;48(3):263-79.

Sheward S, Williams ID. The impact of alternative weekly collections on waste arisings: an English case study. Proceedings of the Thirteenth International Waste Management and Landfill Symposium, S. Margherita di Pula, Cagliari, Sardinia, Italy, October 3/7, ISBN: 978-88-6265-000-7; 2011. [Paper 013].

Simonetto EO, Borenstein D. A decision support system for the operational planning of solid waste collection. Waste Manage 2007; 27:1286-97.

Timlett R, Williams ID. Public participation and recycling performance in England: a comparison of tools for behaviour change. Resour Conserv Recycl 2008;52(4):622-34.

Timlett R, Williams ID. The ISB model (infrastructure, service, behaviour): a tool for waste practitioners. Waste Manage 2011;31(6):1381-92.

Tucker P, Grayson J, Spiers D. Integrated effects of a reduction in collection frequency for a kerbside newspaper recycling scheme. Resour Conserv Recycl 2001;31(2):149-70.

Uzzel D, Räthzel N. Transforming environmental psychology. J Environ Psychol 2009;29(3):340-50.

Wang FS, Richardson AJ, Roddick FA. Relationships between set-out rate, participation rate and set-out quantity in recycling programs. Resour Conserv Recycl 1997;20: 1-17.

WasteDataFlow. Available via http://www.wastedataflow.co.uk/2007. [date of last access 18/2/2008].

Wertz KL. Economic factors influencing households' production of refuse. J Environ Econ Manage 1976;2(4):26372.

Williams ID. Experiences of co-operative research studies between universities and local authorities. Proceedings of the Twelfth International Waste Management and Landfill Symposium, S. Margherita di Pula, Cagliari, Sardinia, Italy, October 5/9, ISBN: 978-88-6265-007-6; 2009. [Paper No. 008].

Williams ID, Kelly J. Green waste collection and the public's recycling behaviour in the Borough of Wyre, England. Resour Conserv Recycl 2003;38(2):139-59.

Wilson CDH, Williams ID. Kerbside recycling: a case study from the north-west of England. Resour Conserv Recycl 2007;52(2):381-94. 
Woodard R, Harder MK, Bench M, Philip M. Evaluating the performance of a fortnightly collection of household waste separated into compostables, recyclates and refuse in the south of England. Resour Conserv Recycl 2001;31(3):265-84

Worthington AC, Dollery BE. Measuring efficiency in local government: an analysis of New South Wales municipalities' domestic waste management function. Policy Stud J 2001;29(1):232-49.

WRAP. Case studies, Courtauld Commitment Phase 1 (2005-2010), Oxon, WRAP. online http://www.wrap.org.uk/sites/files/wrap/CC\%20Case\%20Studies\%2C\%2019\%20Aug\% 202010\%20final.pdf2010. [date of last access 9/7/12].

Tables

Table 1- Index of multiple deprivation (IMD) rankings for villages covered by the trials (IMD, 2007).

\begin{tabular}{llll}
\hline $\begin{array}{l}\text { Lower super output areas } \\
\text { (LSOA) }\end{array}$ & $\begin{array}{l}\text { LSOA } \\
\text { code }\end{array}$ & $\begin{array}{l}\text { National } \\
\text { ranking }\end{array}$ & District ranking/307 \\
\hline Kings Bromley & E1029509 & 24,772 & 30 \\
Armitage with Handsacre 1 & E1029481 & 18,718 & 13 \\
Armitage with Handsacre 2 & E1029480 & 23,651 & 28 \\
Armitage with Handsacre 3 & E1029482 & 19,450 & 20 \\
\hline
\end{tabular}

Table 2 - Summary of household waste collection trials in Lichfield held in 2009.

\begin{tabular}{|c|c|c|c|c|}
\hline System & $\begin{array}{l}\text { Container(s) } \\
\text { supplied }\end{array}$ & Materials collected & $\begin{array}{l}\text { Collection } \\
\text { frequency }\end{array}$ & Change being made \\
\hline Existing kerbside recycling & $\begin{array}{l}551 \text { green box } \\
38 \text { I green box }\end{array}$ & $\begin{array}{l}\text { Paper and cardboard } \\
\text { Mixed glass, steel and aluminium cans and mixed plastics }\end{array}$ & Weekly & None \\
\hline $\begin{array}{l}\text { Trial A (single stream, fully } \\
\text { comingled) }\end{array}$ & $\begin{array}{l}240 \text { I blue } \\
\text { wheeled bin }\end{array}$ & $\begin{array}{l}\text { Mixed glass, steel and aluminium cans and mixed plastics, } \\
\text { paper and cardboard }\end{array}$ & Fortnightly & Less sorting; increased collection frequency \\
\hline Trial B (dual stream) & $\begin{array}{l}2401 \text { blue } \\
\text { wheeled bin } \\
551 \text { green box } \\
381 \text { green box }\end{array}$ & $\begin{array}{l}\text { Mixed glass, steel and aluminium cans and mixed plastics } \\
\text { Cardboard } \\
\text { Paper }\end{array}$ & Fortnightly & $\begin{array}{l}\text { Increased collection frequency; larger and } \\
\text { more containers }\end{array}$ \\
\hline
\end{tabular}

Table 3 - Comparison of participation monitoring and set-out rates for the two trial rounds in Lichfield District.

\begin{tabular}{|c|c|c|c|c|c|}
\hline \multirow[t]{2}{*}{ Trial } & \multirow[t]{2}{*}{$\begin{array}{l}\text { Number of } \\
\text { properties }\end{array}$} & \multicolumn{2}{|l|}{ Pre-trial } & \multicolumn{2}{|c|}{$\begin{array}{l}3 \text { months after start of } \\
\text { trial }\end{array}$} \\
\hline & & $\begin{array}{l}\text { Number of } \\
\text { participants }\end{array}$ & $\begin{array}{l}\text { Set-out } \\
\text { ratio }(\%)\end{array}$ & $\begin{array}{l}\text { Number of } \\
\text { participants }\end{array}$ & $\begin{array}{l}\text { Set-out } \\
\text { ratio (\%) }\end{array}$ \\
\hline $\begin{array}{l}\text { Single } \\
\text { stream } \\
\text { (A) }\end{array}$ & 1175 & 1022 & 87 & 1116 & 95 \\
\hline $\begin{array}{l}\text { Dual } \\
\text { stream } \\
\text { (B) }\end{array}$ & 975 & 838 & 86 & $878 \mid$ & 96 \\
\hline
\end{tabular}

Table 4 - Weights of recyclates collected each fortnight March-August 2009 (kg per household).

\begin{tabular}{lllllllllll}
\hline Trial & \multicolumn{1}{l}{ Collection period } \\
\cline { 2 - 10 } & 1 & 2 & 3 & 4 & 5 & 6 & 7 & 8 & 9 & 10 \\
\hline Single stream (A) & 12.2 & 11.3 & 11.2 & 11.0 & 11.7 & 10.9 & 10.5 & 10.6 & 12.0 & 11.3 \\
Dual stream (B) & 11.8 & 11.0 & 11.4 & 11.3 & 11.5 & 12.0 & 10.9 & 12.8 & 12.4 & 13.7 \\
\hline
\end{tabular}

Table 5 - Weight of recyclates collected each fortnight on Round 2 in 2008 and 2009 (kg per household).

\begin{tabular}{|c|c|c|c|c|c|c|c|c|c|c|}
\hline \multirow[t]{2}{*}{ Trial } & \multicolumn{10}{|c|}{ Collection period } \\
\hline & 1 & 2 & 3 & 4 & 5 & 6 & 7 & 8 & 9 & 10 \\
\hline 2008 (weekly box collection) & 10.4 & 10.6 & 9.5 & 9.9 & 9.8 & 10.7 & 8.9 & 10.7 & 9.1 & 11.1 \\
\hline 2009 (fortnightly single steam bin collection) & 12.2 & 11.3 & 11.2 & 11.0 & 11.7 & 10.9 & 10.5 & 10.6 & 12.0 & 11.3 \\
\hline
\end{tabular}


Table 6 - Weight of recyclates collected each fortnight on Round 3 (dual stream) in 2008 and 2009 (kg per household).

\begin{tabular}{|c|c|c|c|c|c|c|c|c|c|c|}
\hline \multirow[t]{2}{*}{ Trial } & \multicolumn{10}{|c|}{ Collection period } \\
\hline & 1 & 2 & 3 & 4 & 5 & 6 & 7 & 8 & 9 & 10 \\
\hline 2008 (weekly box collection) & 11.0 & 11.0 & 11.8 & 10.8 & 10.8 & 10.8 & 9.2 & 10.2 & 10.9 & 11.9 \\
\hline 2009 (fortnightly box/bin collection) & 11.8 & 11.0 & 11.4 & 11.3 & 11.5 & 12.0 & 10.9 & 12.8 & 12.4 & 13.7 \\
\hline
\end{tabular}

Table 7- Average daily total weight (tonnes) of residual waste collected in the Trial A area during the collection periods in 2008 and 2009.

\begin{tabular}{lllllllllll}
\hline Trial & \multicolumn{1}{l}{ Collection period } & \multicolumn{1}{l}{} \\
\cline { 2 - 10 } & 1 & 2 & 3 & 4 & 5 & 6 & 7 & 8 & 9 \\
\hline 2008 (weekly collection) & 21.34 & 17.70 & 25.72 & 28.30 & 16.68 & 19.32 & 19.62 & 21.04 & 25.82 & 20.20 \\
2009 (fortnightly collection) & 18.66 & 19.34 & 19.32 & 18.54 & 18.54 & 19.14 & 18.34 & 18.66 & 19.00 & 18.70 \\
\hline
\end{tabular}

Table 8 - Average daily total weight (tonnes) of residual waste collected in the Trial B area during the collection periods in 2008 and 2009.

\begin{tabular}{|c|c|c|c|c|c|c|c|c|c|c|}
\hline \multirow[t]{2}{*}{ Trial } & \multicolumn{10}{|c|}{ Collection period } \\
\hline & 1 & 2 & 3 & 4 & 5 & 6 & 7 & 8 & 9 & 10 \\
\hline 2008 (weekly collection) & 16.70 & 16.12 & 19.90 & 16.16 & 18.34 & 16.88 & 14.32 & 12.76 & 17.60 & 14.32 \\
\hline 2009 (fortnightly collection) & 18.10 & 14.14 & 19.86 & 14.62 & 18.98 & 13.96 & 13.26 & 13.76 & 13.28 & 17.96 \\
\hline
\end{tabular}

Table 9 - Overall average weights of residual waste sent to landfill sites in 2008 and 2009 in the trial areas.

\begin{tabular}{|c|c|c|c|c|}
\hline \multirow[t]{2}{*}{ Trial } & \multicolumn{2}{|c|}{ Round 2, Trial A } & \multicolumn{2}{|c|}{ Round 3, Trial B } \\
\hline & $\begin{array}{l}\text { Average daily } \\
\text { weight } \\
\text { (tonnes) }\end{array}$ & $\begin{array}{l}\text { Average weight per } \\
\text { household per } \\
\text { week }\end{array}$ & $\begin{array}{l}\text { Average daily } \\
\text { weight } \\
\text { (tonnes) }\end{array}$ & $\begin{array}{l}\text { Average weight per } \\
\text { household per } \\
\text { week }\end{array}$ \\
\hline 2008 & 21.57 & 9.17 & 1631 & 7.09 \\
\hline 2009 & 18.82 & 8.00 & 15.79 & 6.86 \\
\hline
\end{tabular}

Table 10 - Total hours worked per collection crew member on the trial collection rounds in 2009.

\begin{tabular}{llllllllll}
\hline Trial & \multicolumn{2}{l}{ Collection week } & & & & & & \\
\cline { 2 - 9 } & 1 & 2 & 3 & 4 & 5 & 6 & 7 & 8 & 9 \\
\hline $\begin{array}{c}\text { Single } \\
\text { stream (A) } \\
\begin{array}{c}\text { Dual } \\
\text { stream (B) }\end{array}\end{array}$ & 30.00 & 29.00 & 29.36 & 28.33 & 28.27 & 28.00 & 29.60 & 28.45 & 29.10 \\
\hline
\end{tabular}

Table 11 - Weight of recyclates collected (in kg per hour worked) for both trial collection rounds in 2009.

\begin{tabular}{|c|c|c|c|c|c|c|c|c|c|c|}
\hline \multirow[t]{2}{*}{ Trial } & \multicolumn{10}{|c|}{ Collection week } \\
\hline & 1 & 2 & 3 & 4 & 5 & 6 & 7 & 8 & 9 & 10 \\
\hline Single stream (A) & 467.0 & 448.3 & 437.3 & 447.6 & 474.4 & 449.3 & 408.1 & 426.7 & 474.2 & 454.6 \\
\hline Dual stream (B) & 347.3 & 355.6 & 348.4 & 313.2 & 335.9 & 289.0 & 229.7 & 385.8 & 376.9 & 332.4 \\
\hline
\end{tabular}

Table 12 - Estimated best performance by collection frequency and method (the best performing system is flagged by $\star)$.

\begin{tabular}{|c|c|c|c|c|c|c|}
\hline & $\begin{array}{l}\text { Health, safety and } \\
\text { welfare of crew }\end{array}$ & $\begin{array}{l}\text { Productivity (hours } \\
\text { worked) }\end{array}$ & $\begin{array}{l}\text { Productivity (weight of recyclates } \\
\text { collected } \mathrm{h}^{-1} \text { ) }\end{array}$ & $\begin{array}{l}\text { Maximum yield of } \\
\text { recyclates }\end{array}$ & Cost-effectiveness & Simplicity \\
\hline \multicolumn{7}{|l|}{$\begin{array}{l}\text { Weekly collection; kerbside } \\
\text { box recycling }\end{array}$} \\
\hline AWC $C^{\mathrm{a}}$; dual stream & & & & $\star$ & & \\
\hline
\end{tabular}




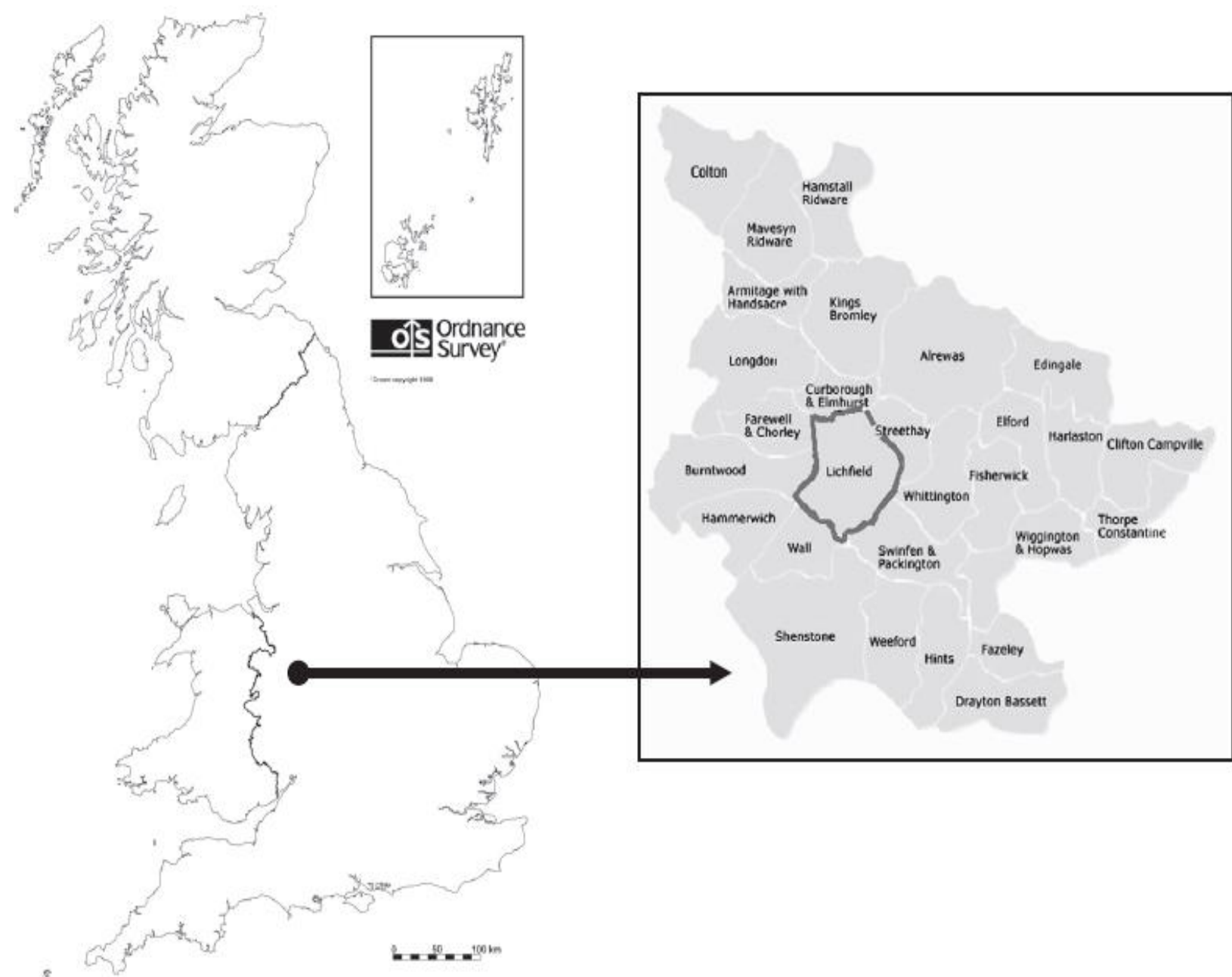

Fig. 1. Relative location of Lichfield in the UK; panel shows Parish Council areas in Lichfield District. Left hand map reproduced from Ordnance Survey map data by permission of the Ordnance Survey (c) Crown copyright 2010.

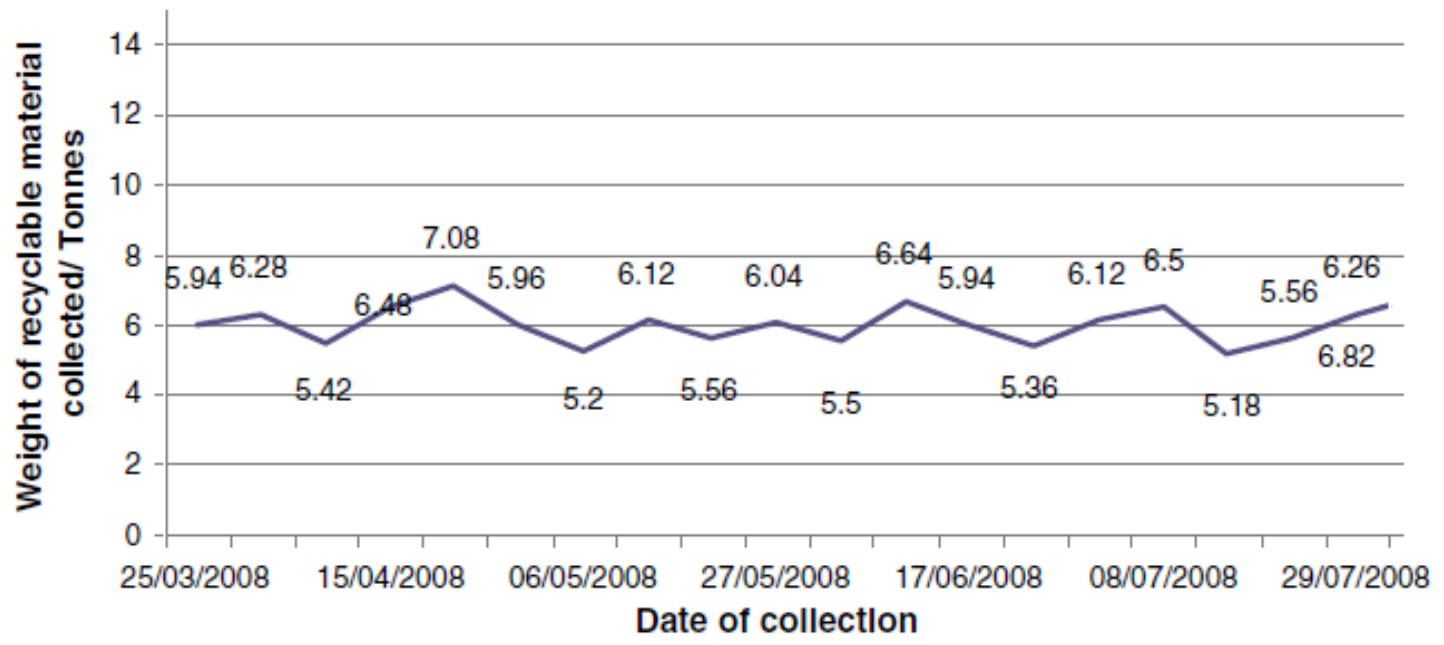

Fig. 2. Quantity of recyclates (in tonnes) collected between 29 March and 8 Aug 2008 on recycling Round 2. 


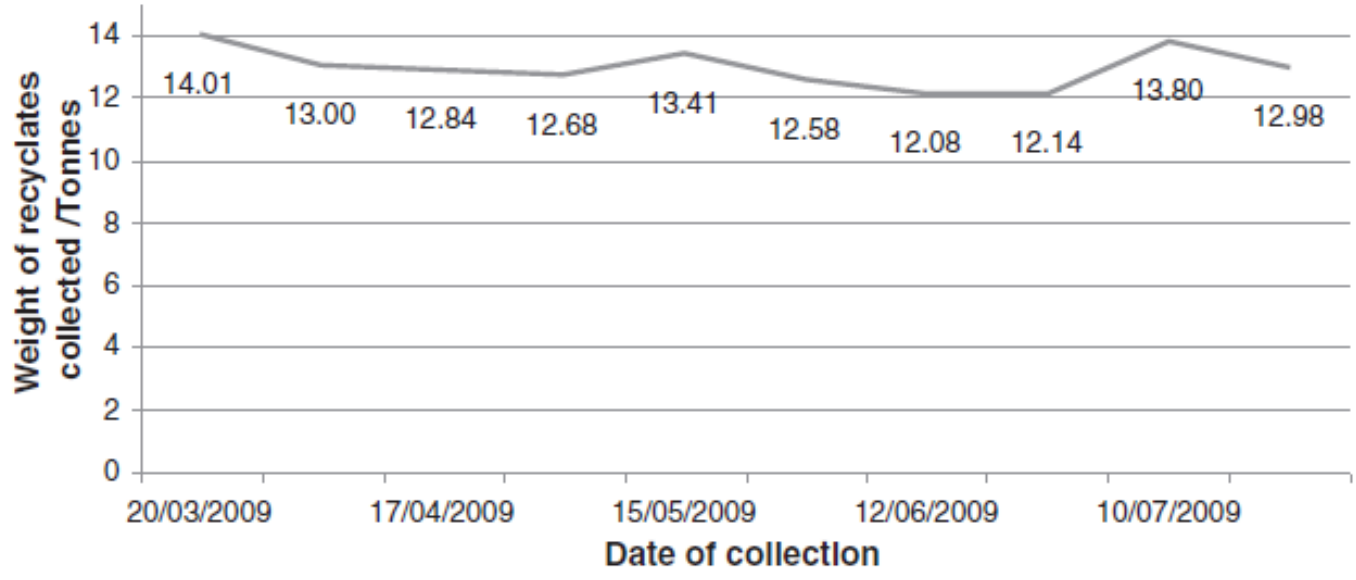

Fig. 3 Daily total weight (in tonnes) of recyclates collected on Trial A (single stream) between 29 March and 1 Aug 2009.

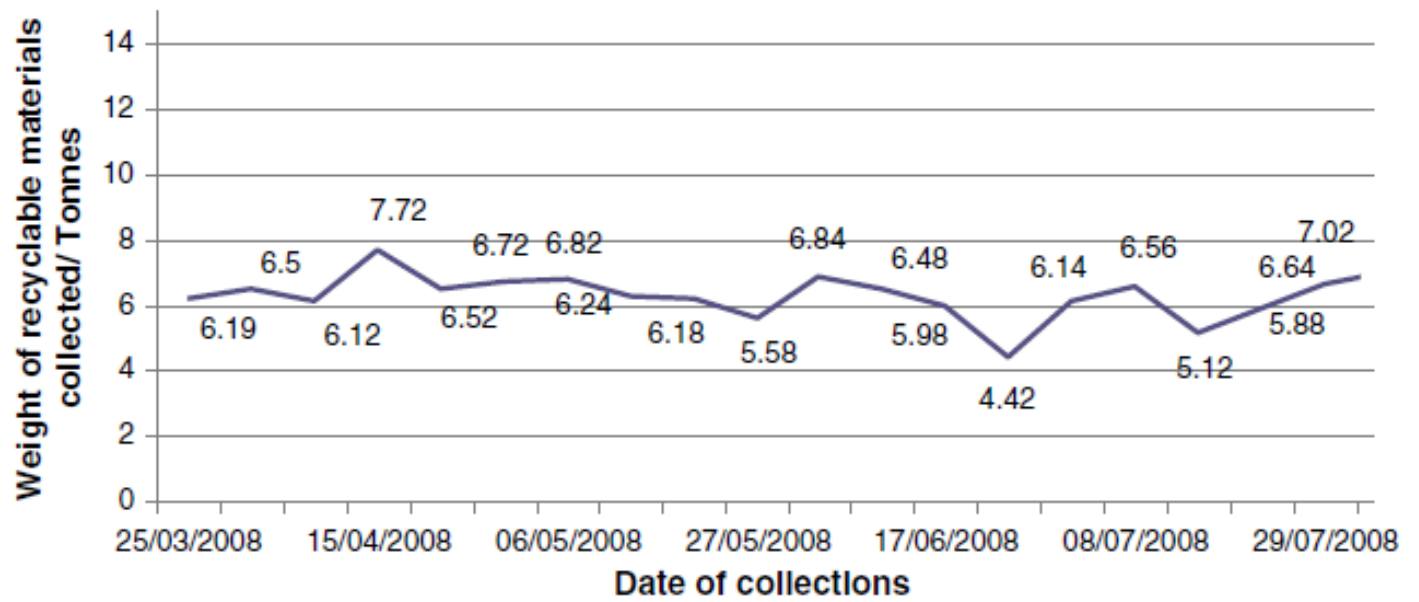

Fig. 4 Quantity of recyclates (in tonnes) collected between 29 March and 8 Aug 2008 on recycling Round 3.

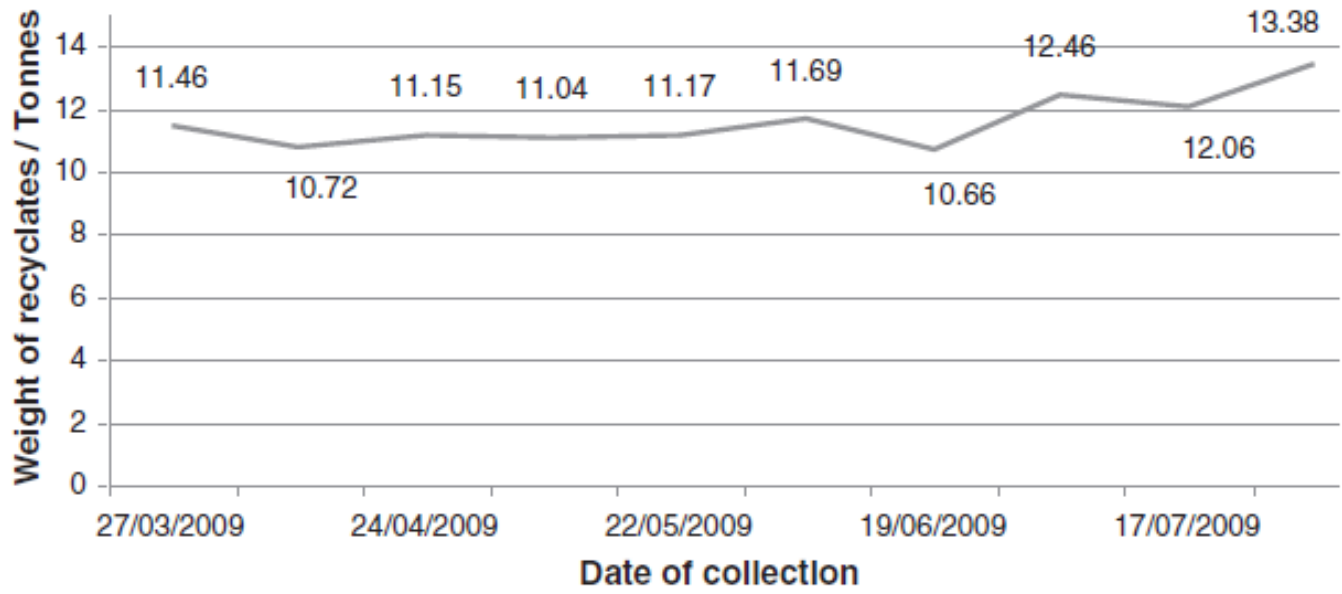

Fig. 5 Daily total weights (in tonnes) of recyclates collected on the 10 collection dates between 27 March and 31 July 2009 on Trial B (dual stream). 